

Image reproduced, with permission, from Nature Gomez, C. et al. (doi:10.1038/ nature 07020) ( (2008) Macmillan Publishers Ltd. All rights reserved.

\title{
DEVELOPMENT
}

\section{Ticking off new segments}

Each vertebrate species has a characteristic number of segments along the body axis - humans have only 33 whereas snakes can have over 300 (see image). What developmental genetic principles lie behind these precise species-specific numbers? A paper that compares the molecular details of segment formation across several species now shows that they all generate their segments in a similar way, but that they make different numbers of somites chiefly by varying the ratio between the rate of somite formation and the rate of growth of the somite-generating tissue.

Somites are blocks of mesoderm that are generated in anteriorposterior sequence as tissue is rhythmically pinched off the presomitic mesoderm (PSM) at the tail end of the embryo. The process is controlled by a gene-expression oscillator in the cells of the PSM; this 'segmentation clock' drives the cyclical production of several molecules, including those in the Notch, Wnt and fibroblast growth factor (FGF) pathways. In each tick of the clock, one additional somite is produced.

To understand how the differences in somite number arise, the authors compared the expression of various signalling molecules involved in somitogenesis across four vertebrate species: corn snakes, which have 315 segments, and zebrafish, chickens and mice, each of which has fewer than 70 vertebrae. Most of the segmentation-clock genes in snake embryos were expressed in the expected pattern, and in situ hybridization against Lunatic fringe RNA provided evidence of oscillations in this species.

The number of somites depends on how fast the segmentation clock ticks and how long the PSM continues in existence as a source of new somites. The authors estimate here that the time it takes to generate a somite is $100 \mathrm{~min}$ in the snake versus 30,90 and $120 \mathrm{~min}$ in the zebrafish, chicken and mouse, respectively. The snake, however, has an exceptionally slow rate of cell proliferation in its PSM. The snake PSM carries on generating somites for only slightly more cell-division cycles than that of a mouse, for example - about 21 celldivision cycles compared with about 17 - but in the course of its 21 slow division cycles it chalks up almost five times as many ticks of its relatively rapid segmentation clock, and thus makes almost five times as many somites. So there are more segments in the snake not because its PSM cells multiply more quickly or for many more cell-division cycles than in the chick or mouse, but because they grow more slowly relative to the rate at which the segmentation clock ticks.

This work has shown that the basic clock and wave-front model operates similarly across the four species examined, and therefore possibly across all vertebrates. The number of PSM cell generations, although small in the zebrafish, does not vary much across the three amniote species (the snake, chick and mouse). Instead, the spectacular differences of segment number among these species have emerged through change in the rate of the segmentation clock relative to the rate of the cell-division cycle. Tanita Casci

ORIGINAL RESEARCH PAPER Gomez, C. et al. Control of segment number in vertebrate embryos. Nature 18 Jun 2008 (doi:10.1038/ nature07020)

FURTHER READING Dequéant, M.-L. \&

Pourquié, O. Segmental patterning of the vertebrate embryonic axis. Nature Rev. Genet. 9, 370-382 (2008) 